\title{
Mechanical properties of a balsa wood veneer structural sandwich core material
}

\author{
Chao $\mathrm{Wu}^{1,2}$, Niloufar Vahedi ${ }^{2}$, Anastasios P. Vassilopoulos ${ }^{2}$ and Thomas Keller ${ }^{2} * *$ \\ ${ }^{1}$ School of Transportation Science and Engineering, Beihang University, 37 Xueyuan Road, \\ Beijing 100191, China, Email: wuchao@buaa.edu.cn \\ ${ }^{2}$ Composite Construction Laboratory (CCLab), École Polytechnique Fédérale de Lausanne \\ (EPFL), Station 16, Bâtiment BP, CH-1015 Lausanne, Switzerland \\ * Corresponding author email: thomas.keller@epfl.ch; Tel.: +41 216933226
}

\begin{abstract}
Balsa wood is an appropriate core material for structural sandwich applications due to its high strength- and stiffness-to-weight ratios. However, the mechanical properties vary considerably owing to the inherent scattering of natural wood materials. One approach to reduce this scatter and tailor the mechanical properties according to specific application needs is to recompose the natural material into a veneered material consisting of veneer layers of different grain orientations, which are adhesively bonded together. The mechanical properties of such a veneered balsa wood, composed of alternating $0^{\circ} / 90^{\circ}$ grain orientations, were investigated at ambient temperature according to corresponding standards. The properties were significantly influenced by the orthotropy on the material scale within one veneer layer and on the system scale within the assembled veneer layers. Standardized experimental set-ups and specimen geometries may produce artifacts such as buckling or strain hardening which deviate from the material behavior in real structures. The thin adhesive between the veneer layers did not negatively affect the mechanical behavior since failure occurred within the veneer layers and not in the interfaces.
\end{abstract}

Keywords: Balsa wood; Tensile properties; Compressive properties; Shear properties; Sandwich panel; Core material 


\section{Introduction}

Balsa is one of the lightest wood species used in structural applications, and due to its high strength- and stiffness-to-weight ratios is a preferred material for sandwich panel cores [1-3]. Such panels are found in major load-bearing applications, e.g. hulls of ships and aircraft [4-5] or in the rail, wind energy, aerospace, and defense industries [6]. More recently, balsa wood has been used as a core material for bridge decks [7-9] in bridge construction. One example is the glass fiber-reinforced polymer (GFRP)-balsa sandwich deck installed on a road bridge across the Avançon river in Bex, Switzerland [8]. The sandwich structure is composed of GFRP face sheets and a balsa wood core with end-grain orientation (with the wood fibers transverse to the face sheets) to resist indentation from heavy truck wheel loads. The balsa wood core provides continuous support for the face sheets in this case, thus avoiding stress concentration problems in the intersection of the face sheets and webs of multicellular decks $[10,11]$.

Orthotropic balsa wood used as core material in sandwich panels is subjected to various stress states and a knowledge of the mechanical properties in all loading directions is therefore of critical importance for appropriate design. Kotlarewski et al. [3] investigated the mechanical properties of balsa wood sourced from Papua New Guinea. Static bending, hardness, compression (parallel and perpendicular to the grain) and shear (parallel to grain) experiments were conducted. Specimens were cut from sapwood, preconditioned to $12 \%$ moisture content, and investigated according to ASTM D143-09 [12]. This study indicated that the mechanical properties of balsa wood were closely related to its density. However, high density did not guarantee a superior strength value. Specimens with a density range of $140-150 \mathrm{~kg} / \mathrm{m}^{3}$ exhibited better mechanical properties compared to samples with lower and higher densities. It was also noted that balsa wood from Papua New Guinea exhibited slightly lower strength and stiffness than balsa sourced from South America in terms of modulus of elasticity and shear strength. Chowdhury et al. [13] also conducted experiments concerning the characterization of 
mechanical properties of balsa wood originating from Bangladesh. This research revealed that the mechanical properties of balsa wood were mostly related to the air- dry density of balsa. Osei-Antwi et al. [2] characterized the shear properties of end-grain balsa panels from Ecuador. The effects of the shear plane, density and adhesive joints between lumber blocks on the shear properties of the balsa panels were evaluated. Similarly, the authors found that shear stiffness and strength increased with the increasing density of the balsa. Some specimens exhibited significant ductility due to plastic deformations in the tracheids.

The above-mentioned studies were all conducted using balsa blocks or lumbers. Similar to other wood types [14], the mechanical properties of balsa wood exhibit significant variations in the radial direction of the tree's cross sections and thus considerable scattering, which causes difficulties in the design of sandwich panels incorporating a balsa core. In order to reduce this scatter, a new balsa product was developed for the deck of the above-mentioned Avançon bridge [8]. This balsa core consists of thin veneer layers bonded together with an adhesive. All veneer layers are oriented in the same end-grain direction. The substitution of the larger lumber blocks by thin veneer layers allowed the reduction of density variation thanks to appropriate material selection, thus reducing the scatter of the mechanical properties. Shir Mohammadi et al. [15] compared the fracture toughness of this laminated veneer lumber (LVL) balsa to the toughness of conventional balsa block material. The research demonstrated that LVL balsa material with a good lamination adhesive has improved toughness and fiber bridging effects compared to bulk balsa. However, no systematic investigations and characterization of the mechanical properties of such balsa wood veneers exist to date.

This paper presents a comprehensive experimental study of the tensile, compressive and shear properties of a veneered balsa wood. The material consisted of a series of veneer layers with alternating $0^{\circ} / 90^{\circ}$ grain orientations. A total of 68 experiments were conducted to consider all possible loading directions that could be developed in the core of a sandwich panel. To achieve 
this, three tensile, three compressive and four shear specimen configurations were investigated. The failure modes, stress-strain curves and modulus and strength values were reported. Finally, the design-based $5 \%$ characteristic values, according to Eurocode recommendations, were obtained for each configuration and compared with corresponding values derived from statistical distributions.

\section{Experimental investigation}

\subsection{Materials and moisture content}

The balsa wood used in the present study was BALTEK ${ }^{\circledR}$ VBC provided by $3 \mathrm{~A}$ Composites Core Materials (Sins, Switzerland) [16]. This product consists of balsa veneer layers, which were produced by a rotary peeling process of balsa trunks using a roller pressing bar. Detailed information about the rotary peeling process can be found in [17]. Each veneer layer had a nominal thickness of $6 \mathrm{~mm}$. They were alternatingly stacked in $0^{\circ} / 90^{\circ}$ grain orientations, as shown in Fig. 1, bonded together with a one-component cold-curing and foaming polyurethane (PU) adhesive, Jowapur 687.22, compressed, and cured at room temperature for at least 24 hours.

Specimens were cut from the $1200 \times 150 \times 100$-mm BALTEK ${ }^{\circledR}$ VBC veneer blocks. According to the manufacturer, the average density of BALTEK VBC is $180-240 \mathrm{~kg} / \mathrm{m} 3$.

The specimens were stored in a condition room with a constant temperature of $20{ }^{\circ} \mathrm{C}$ and a relative humidity of $65 \%$ for at least two months to ensure that the moisture content of the specimens was equilibrated. The moisture content was then measured according to ASTM 4442-07 [18] using cubic specimens of $30 \times 30 \times 30 \mathrm{~mm}^{3}$ consisting of five veneer layers. The weights of the cubes were measured immediately after they were taken out of the condition room. Subsequently, the cubes were dried in an oven at a temperature of $105{ }^{\circ} \mathrm{C}$ for at least 48 hours and then weighed. A total of ten cubes were measured; the average measured moisture 
content was $9.1 \%$ with a standard deviation of $0.27 \%$. The average density before and after drying was $186.4 \pm 11.4 \mathrm{~kg} / \mathrm{m}^{3}$ and $170.8 \pm 10.9 \mathrm{~kg} / \mathrm{m}^{3}$, respectively.

\subsection{Tensile experiments}

Three configurations of tensile specimens, T1, T2 and T3, were prepared as shown in Fig. 2. In configuration $\mathrm{T} 1$ the load was applied in the transverse-to-the-layers' direction while in configurations T2 and T3 the load was parallel to the layers, i.e. in T2 parallel to three $90^{\circ} / 0^{\circ} / 90^{\circ}$ and in T3 parallel to three $0^{\circ} / 90^{\circ} / 0^{\circ}$ layers. The detailed dimensions, shown in Fig. 3(a), were determined based on ASTM D3500-14 [19]. A special fixture was manufactured to apply the tensile load to the soft specimens, see Fig. 3(b). The tensile experimental set-up is shown in Fig. 3(c).

All experiments were conducted on an MTS Landmark $25 \mathrm{kN}$ Servohydraulic Material Test System provided by MTS Systems GmbH (Berlin, Germany) with a capacity of $25 \mathrm{kN}$. The built-in load cell was calibrated to $20 \%$ of its full capacity. A video extensometer system comprising a 10-bit Sony XCLU1000 CCD camera connected to a Fujinon HF35SA-1 lens (with a focal length of $35 \mathrm{~mm}$ and an aperture of f1.4-22) was used to measure the axial strains. Black target dots of $1.5-\mathrm{mm}$ diameter were applied on the specimen surface with a gage length of $24 \mathrm{~mm}$ (T1) and $30 \mathrm{~mm}$ (T2, T3), see Fig. 2(b). The video extensometer system captured the relative movements of the three pairs of target dots, which were measured with an accuracy of $\pm 0.005 \mathrm{~mm}$. The load obtained from the MTS load cell and the movement of the targets were recorded at a frequency of $10 \mathrm{~Hz}$. The experiments were performed at a displacement rate of $1 \mathrm{~mm} / \mathrm{min}$. A total of 30 tensile experiments were conducted, with 10 specimens in each direction. 


\subsection{Compressive experiments}

Similar to the tensile specimens, three configurations of compressive specimens, C1, C2 and $\mathrm{C} 3$, were cut from the veneer blocks, as shown in Fig. 4. Five veneer layers were considered in configurations C2 and C3; the dimensions were determined according to ASTM D3501-05 [20]. A special fixture was designed to load the specimens in compression via the tensile load of the machine, see Fig. 5(a). Stoppers were used at both ends of the specimen to block any horizontal movement. The experimental set-up of the compressive experiments is shown in Fig. 5(b).

The same machine and video extensometer system were used as for the tensile experiments. Pairs of target dots with a gage length of $38 \mathrm{~mm}(50 \mathrm{~mm})$ were applied to $\mathrm{C} 1$ (C2, C3) specimens, see Fig. 4(a). Measurement frequency and displacement rate were the same as for the tensile experiments. Eighteen compressive experiments were conducted, i.e. six experiments for each of the three configurations.

\subsection{Shear experiments}

The possible shear stress directions and corresponding four configurations of shear specimens are shown in Figs. 6 and 7. The dimensions of the shear specimens were defined according to ASTM D5379-12 [21]. S1 specimens consisted of two veneer layers $\left(0^{\circ} / 90^{\circ}\right)$ with a corresponding thickness of $12 \mathrm{~mm}$. The same thickness was adopted for the remaining configurations.

A special shear-loading fixture was manufactured to transfer the tensile load of the machine to a shear load on the specimen, see Fig. 8(a). The experimental set-up of the shear experiments is shown in Fig. 8(b).

The loading and video extensometer systems, displacement rate and measurement frequency were the same as in the other experiments. Four target dots were applied on the shear specimens as shown in Fig. 7(a). In S1, S3 and S4 they were located at the four corners of a $12 \times 12 \mathrm{~mm}^{2}$ 
square area around the center of the specimen. For $\mathrm{S} 2$, the size of the square area was $6 \times 6 \mathrm{~mm}^{2}$, to ensure that the target dots were on the same veneer layer. The shear strain, $\gamma$, was obtained from the deformed shape $A^{\prime} B^{\prime} C^{\prime} D^{\prime}$, see Fig. 9, as follows [2]:

$\gamma=\alpha+\beta$, where $\alpha=\frac{A A^{\prime}}{A C}$ and $\beta=\frac{D D^{\prime}}{C D}$

Considering that angles $\alpha$ and $\beta$ are small, it is safe to assume that $\cos \alpha=\alpha$ and $\cos \beta=\beta$.

The shear stress was calculated from the load divided by the cross-sectional area between the notches. A total of twenty shear experiments were conducted, i.e. five experiments for each of the four configurations.

\section{Experimental Results and Discussions}

\subsection{Tensile properties}

\subsubsection{Failure modes}

The failure modes of the tensile specimens are shown in Fig. 10. T1 specimens failed in one of the veneer layers in the transverse grain direction. In the T2 and T3 specimens, tensile failures occurred in the $90^{\circ}$ veneer layer (with grain direction transverse to load), while shear failures were observed in the $0^{\circ}$ veneer layers (with grain direction parallel to load).

\subsubsection{Tensile stress-strain curves, modulus and strength}

Selected representative tensile stress-strain curves of T1, T2 and T3 specimens are shown in Fig. 11. The strains are average values of the three measurements in the transverse direction. All specimens exhibited a linear elastic behavior under tensile loading. The elastic modulus was derived from the slope of the curve over a strain range of 0.001-0.003 according to ASTM D3039 [22] and the peak stresses were considered as the tensile strength. The corresponding results are summarized in Table 1.

Configuration $\mathrm{T} 1$ exhibited a much lower average modulus and strength than T2 and T3 since 
the properties were dominated by the transverse-to-grain direction. Configuration T3 with two $0^{\circ}$ layers showed higher values than $\mathrm{T} 2$ with only one $0^{\circ}$ layer. However, the average modulus and strength of T3 were only $1.28 \times$ and $1.21 \times$ higher than those of T2, although the $0^{\circ}$ crosssectional area of T3 was $2 \times$ that of T2. The deviation of this factor of 2 may be explained regarding the strength by the sequential failure of the two $0^{\circ}$ layers and regarding the modulus by the fact that the $90^{\circ}$ layers already failed at very low strains, i.e. below the strain interval at which the modulus was calculated. In both cases the responses were influenced by resulting eccentricities.

\subsection{Compressive properties}

\subsubsection{Failure modes}

The failure modes of $\mathrm{C} 1, \mathrm{C} 2$ and $\mathrm{C} 3$ specimens are shown in Fig. 12. Specimens $\mathrm{C} 1$ failed during buckling, exhibiting the typical buckling mode of a column fixed on both sides. Correspondingly, second-order bending moment peaks developed at (approximately) midheight and the fixation points, which led to crack initiation on the tensioned side transverse to the grain at these three locations. The cracks initiated and subsequently propagated in the veneer layer and not in the adhesive interface between two veneer layers.

C2 specimens, exhibiting the $90^{\circ}$ layers on the outer sides, also failed during buckling and associated seconder-order bending. A series of shear cracks appeared in the mid $90^{\circ}$ veneer layer due to the shear stresses that developed during the bucking process. This damage reduced the composite action between the adjacent layers which, compared to the $\mathrm{C} 1$ configuration, changed the buckling mode to that of a column with hinged supports, i.e. a rotation at the supports occurred. Final failure of all C2 specimens occurred by fracture of the outer veneer layer on the tension side and crushing on the compression side at approximately mid-height.

$\mathrm{C} 3$ specimens were more compact due to the greater number of $0^{\circ}$ layers that they comprised 
and they failed by a combined crushing and kinking of all layers with associated delamination. It should be noted that, owing to the nature of this balsa veneer material, it is almost impossible to achieve a desirable crushing failure mode for $\mathrm{C} 1$ and $\mathrm{C} 2$ configurations when standard dimensions are used. Larger or shorter, i.e. more compact, specimens could be used to determine whether pure crushing failure can actually be achieved.

\subsubsection{Compressive stress-strain curves, modulus and strength}

Selected representative compressive stress-strain curves are shown in Fig. 13. The strains are average values of the three or five measurements in the transverse direction. C1 specimens initially exhibited a linear response until they started to buckle, see Fig. 13(a). Due to the horizontally layered configuration and thus low axial stiffness, the specimens were able to sustain large lateral deformations. The axial stress continued to increase nonlinearly with increasing strain until crack initiation occurred as described above. Subsequently the axial stress, i.e. the load, decreased during crack propagation until failure as described above. The compressive stress of $\mathrm{C} 2$ specimens also linearly increased with increasing strain up to a peak

point, see Fig. 13(b). The specimens then started to buckle with gradually increasing lateral deformation. Due to the flexural stresses developed during the buckling process, shear cracks appeared in the middle $90^{\circ}$ veneer layer and the axial stress (load) gradually decreased until final failure occurred as described above. C3 specimens also exhibited a linear elastic stressstrain response up to a peak point, see Fig. 13(c), after which the stress suddenly dropped due to the crushing failure.

The results of all compressive experiments are listed in Table 2. The modulus was determined by estimating the slope of the stress-strain curve's linear elastic region in the range between 5 and $35 \%$ of the ultimate load according to ASTM D3501 [20]. The stress at the peak point of the stress-strain curve was defined as the strength. For C1 and C2 specimens buckling stresses 
were also defined and assumed as being the stress at the end of the linear elastic stage. For C2 specimens this value was almost the same as that of the peak stress.

Similar to the tension results, configuration $\mathrm{C}$, loaded only in the transverse-to-the-grain direction, exhibited much lower strength and stiffness than the $\mathrm{C} 1$ and $\mathrm{C} 2$ configurations. The buckling stress was almost half of the compressive strength. $\mathrm{C} 3$ specimens, with three $0^{\circ}$ layers, exhibited higher strength and stiffness than $\mathrm{C} 2$ specimens with only two $0^{\circ}$ layers. The $\mathrm{C} 3$ average modulus and strength values were $1.25 \times$ and $1.50 \times$ higher than the $C 2$ values, the former deviating from the theoretical value of 1.5 depending on the number of $0^{\circ}$ layers. This difference can be attributed to the standard deviations of up to $20 \%$ of the average values.

\subsection{Shear properties}

\subsubsection{Failure modes}

The failure modes of S1, S2, S3 and S4 specimens are shown in Fig. 14. In S1 specimens, horizontal cracks initiated in the $0^{\circ}$ veneer layer from the notches of the specimens. Subsequently, under increasing load, the continuous grains of the $0^{\circ}$ layer between the notches deformed to an s-shape and acted as tendons. The specimen finally failed at the locations of maximum curvature of these s-bands. The $90^{\circ}$ veneer layer (on the back of the specimens in Fig. 14) failed much earlier via a vertical shear crack connecting the top and bottom notches. In S2 specimens, the $90^{\circ}$ veneer layer failed first in shear and the load was then sustained by the fibers in the $0^{\circ}$ veneer layer by the same s-shaped tendon mechanism as exhibited in $\mathrm{S} 1$ specimens. Therefore, the same failure mode occurred, i.e. tensile failure at the location of maximum curvature of the s-shape deformed layer where tensile stresses from the tendon action and local bending were superposed. In S3 specimens, failure initiated with vertical cracks in the two $90^{\circ}$ layers on both the left and right sides of the notches, which resulted in the separation of a square element from the specimen. As the load was increased, the square element started 
to rotate until it fractured in the $0^{\circ}$ layer between the notches. S4 specimens failed in the $90^{\circ}$ layer between the notches.

\subsubsection{Shear stress-strain curves, modulus and shear strengths}

The typical shear stress-strain curves of all configurations are shown in Fig. 15. For S1, S3 and S4 specimens, the shear stress initially increased almost linearly with increasing shear strain up to a peak point, see Fig. 15 (a). The nonlinearity was caused by the damage accumulation during the progressive failure process. After the peak point, the shear stresses of S1, S3 and S4 specimens dropped as the strain increased. S1 specimens lost their strength gradually because of the gradual fracture of the "tendon"' layer. In S3 specimens, a first drop in shear stress was caused by the crack formation in the two $90^{\circ}$ layers on both the left and right sides of the notches. A second drop occurred due to the complete separation of the square element from the specimen, as described above. After this second drop, the specimens exhibited a hardening behavior that however was not related to the material, i.e. the separated square element was stuck between the grips and rotated and thus increased the resistance until complete fracture of the element occurred. S4 specimens exhibited a progressive fracture of the $90^{\circ}$ layer as sheer stress decreased.

In $\mathrm{S} 2$ specimens, the shear stress also increased almost linearly until the $90^{\circ}$ layer started fracturing, see Fig. 15 (b). After the $90^{\circ}$ layer completely failed, the shear load was sustained only by the $0^{\circ}$ veneer layer, i.e. the vertical component of its tension force, which induced strain hardening until final failure in the $0^{\circ}$ layer occurred. In this case, in contrast to the S3 behavior, strain hardening was primarily caused by the material behavior, as it may also be activated in a real sandwich structure and not just represent an artifact of the experimental setup. Furthermore, in contrast to the S1, S3 and S4 configurations, S2 specimens exhibited a significant ductile behavior, i.e. the ability to sustain inelastic deformation without loss of 
resistance.

The experimental results of all shear experiments are listed in Table 3. The maximum shear stress of the stress-strain curve was defined as the shear strength. The shear modulus was determined from the slope of the stress-strain curves over a strain range of 0.004 with the lower strain point being in the range of $0.0015-0.0025$ according to ASTM D5379 [21]. For S2 specimens, the stress at 0.05 shear strain was also extracted, which could represent the strength causing only limited activation of the tendon mechanism. The average coefficients of variation $(\mathrm{COV})$ for shear strength and shear modulus were $12 \%$ and $22 \%$, respectively (average values of all four configurations). Comparing these values to the results published in [2] for commercial end-grain balsa panels, i.e. COV values of $33 \%$ for shear strength and $28 \%$ for shear modulus, demonstrated the more uniform shear properties of the LVL material.

S1 and S2 specimens exhibited a significantly higher shear strength and modulus than S3 and S4 specimens due to the activation of the tendon mechanism. The modulus of S1, which was influenced by the axial and bending stiffness of the activated $0^{\circ}$ tendon, was higher than that of $\mathrm{S} 2$ since the cross section of the $0^{\circ}$ layer $\left(12 \times 6 \mathrm{~mm}^{2}\right.$ in each case $)$ was placed vertically and not horizontally as in the case of S2. For the same reason, the strength of S1 was however lower than that of S2 since the activated bending moment and thus additional bending-tensile stresses were higher in S1 than in S2. The S3 configuration exhibited better properties than S4 since the shear force between the notches acted parallel and not transverse to the grain as in the latter case.

\section{Characteristic values of strength and modulus}

\subsection{Statistical distributions}

Many design codes are based on characteristic values of the material properties, defined as the $5 \%$ fractile values [23]. These values are dependent on the type of statistical distribution that 
the data follows. Quantile-quantile (Q-Q) plots are used in the following to find the best distributions for the experimental data presented above. In this goodness-of-fit method, the quantiles of the data are set against the quantiles of a specific distribution [24]. If the two sets originate from the same distribution, the data points should fall approximately along the reference line [24]. An example of a Q-Q plot is given in Fig. 16, which shows the quantiles of the strength data of the T1 specimens plotted against those of the normal distribution. The corresponding R-squared value representing the goodness of the normal distribution is then calculated, resulting in a value of 0.92 in this case, see Fig. 16. The R-squared values derivedfrom Q-Q plots of the strength data of all the specimen configurations versus normal, lognormal, Weibull and gamma distributions are illustrated in Fig 17.

The Weibull distribution exhibited the highest R-squared values among all distributions for all specimen configurations. For the modulus data, the results of the Q-Q plots were the same and Weibull was also shown to be the best fitting distribution.

\subsection{Eurocode EN1990}

Civil engineering structures in Europe, such as bridges or buildings, are normally designed based on the Eurocode. According to Eurocode EN1990 [23], the 5\% characteristic values are based on a normal distribution and calculated as follows:

$X_{k(n)}=m_{x}\left(1-k_{n} V_{x}\right)$

with $X_{k(n)}=$ characteristic value, $m_{x}=$ mean value of $n$ sample results, $k_{n}=$ characteristic fractile factor and $V_{x}=$ coefficient of variation of $X_{n}$. The values of $k_{n}$ depend on the number of samples and are listed in Table 4.

The resulting 5\% characteristic tensile, compressive and shear strength and modulus of all configurations calculated using Eq (1) are presented in Table 5. These values take into account 
the scatter of the experimental data and statistical uncertainty associated with the number of experiments [23]. It can be seen that the scattering nature of the wood resulted in characteristic values considerably lower than the mean values shown in Tables 1-3.

\subsection{Comparison and discussion}

The $5 \%$ characteristic values of modulus and strength for all configurations were calculated based on the Weibull and normal distributions and compared with corresponding values obtained from Eurocode EN1990, see Table 5.

The differences in the results are shown in Fig. 18 for the case of the characteristic modulus of the $\mathrm{C} 1$ configuration. The best-fit Weibull distribution gave higher values compared to the normal distribution due to its narrower shape. The differences between mean value and characteristic value of normal and Weibull distributions were $1.5 \%$ and $2.4 \%$, respectively. The Eurocode values based on the normal distribution were slightly lower (1.6\%) than the corresponding values from the normal distribution since the latter are based on $k_{n}=1.64$, i.e. on an infinite number of samples, see Table 4.

\section{Conclusions}

This paper presents a comprehensive experimental study to characterize the tensile, compressive and shear properties of a veneered balsa wood product, BALTEK ${ }^{\circledR}$ VBC, as a core material for sandwich applications. The failure modes, stress-strain curves and modulus and strength values were reported. The following conclusions were drawn:

- The mechanical properties were significantly influenced by the orthotropy on two scales, i.e. on the material scale within one veneer layer and on the system scale within the assembled veneer layers. The material and system orientation with regard to the loading direction must therefore be taken into account in the design verification. 
- It is not easy to obtain the mechanical properties of these veneer materials since standard set-ups and specimen geometries may produce artifacts such as buckling or strain hardening. The material and system responses must be carefully checked as to whether they correspond to the behavior in the real structure to be designed based on these values.

- Although the veneer material is intended to reduce property scatter, the latter was still significant. Due to the scatter, the 5\% characteristic values according to Eurocode EN1990 are significantly reduced.

- The thin adhesive between the veneer layers did not seem to have negatively affected the mechanical behavior; failure occurred within the veneer layers and not in the interfaces. This may however change at elevated temperatures when the temperature approaches the glass transition temperature of the adhesive.

The results of this work demonstrate the advantage of veneered balsa wood material compared to bulk/block-shaped balsa wood when used as core material in sandwich structural elements. Normally the stress state in sandwich cores is multidirectional. Veneered balsa wood can much better adapt to such complex stress conditions and the scatter of the properties is reduced. It should however be taken into account that the specimen sizes were small; the obtained properties, the strengths values in particular, were influenced by size effects and are thus not representative for higher volumes, i.e. cannot be directly applied in the design of balsa cores of large-scale sandwich elements.

\section{Acknowledgments}

The authors gratefully acknowledge the financial support provided by the Swiss Government Excellence Fellowship (20150901), Swiss National Science Foundation (Grant No. 200020_172520), and National Science Foundation of China (51978025, 51911530208). The 
materials used in this study were kindly provided by 3A Composites Core Materials, Sins, Switzerland.

\section{References}

1. Tsoumis G. Science and technology of wood: structure, properties, utilization. New York: Van Nostrand Reinhold; 1991.

2. Osei-Antwi M, De Castro J, Vassilopoulos AP, Keller T. Shear mechanical characterization of Balsa wood as core material of composite sandwich panels. Construction and Building Materials. 2013 Apr 1; 41:231-8.

3. Kotlarewski NJ, Belleville B, Gusamo BK, Ozarska B. Mechanical properties of Papua New Guinea Balsa wood. European Journal of wood and wood products. 2016 Jan 1; 74(1):83-9.

4. Atas C, Sevim C. On the impact response of sandwich composites with cores of Balsa wood and PVC foam. Composite Structures. 2010 Dec 1; 93(1):40-8.

5. Kwon YW, Violette MA, McCrillis RD, Didoszak JM. Transient dynamic response and failure of sandwich composite structures under impact loading with fluid structure interaction. Applied Composite Materials. 2012 Dec 1; 19(6):921-40.

6. Midgley S, Blyth M, Howcroft N, Midgley D, Brown A. Balsa: biology, production and economics in Papua New Guinea. ACIAR Technical Reports Series. 2010(73).

7. Osei-Antwi M, De Castro J, Vassilopoulos AP, Keller T. Structural limits of FRP-Balsa sandwich decks in bridge construction. Composites Part B: Engineering. 2014 Jul 1; 63:77-84. 8. Keller T, Rothe J, De Castro J, Osei-Antwi M. GFRP-Balsa sandwich bridge deck: Concept, design, and experimental validation. Journal of Composites for Construction. 2013 Jul 25; 18 (2):04013043.

9. Dai J, Hahn HT. Flexural behavior of sandwich beams fabricated by vacuum-assisted resin transfer molding. Composite Structures. 2003 Aug 1; 61(3):247-53. 
10. Reising RM, Shahrooz BM, Hunt VJ, Neumann AR, Helmicki AJ, Hastak M. Close look at construction issues and performance of four fiber-reinforced polymer composite bridge decks. Journal of Composites for Construction. 2004 Feb; 8(1):33-42.

11. Triandafilou LN, O'Connor JS. Field issues associated with the use of fiber-reinforced polymer composite bridge decks and superstructures in harsh environments. Structural Engineering International. 2010 Nov 1; 20(4):409-13.

12. ASTM D143-09, Standard Test Methods for Small Clear Specimens of Timber, ASTM International, West Conshohocken, PA, 2009.

13. Chowdhury MQ, Sarker SK, Deb JC, Sonet SS. Timber species grouping in Bangladesh: linking wood properties. Wood science and technology. 2013 Jul 1; 47(4):797-813.

14. Moshtaghin AF, Franke S, Keller T, Vassilopoulos AP. Experimental characterization of longitudinal mechanical properties of clear timber: Random spatial variability and size effects. Construction and Building Materials. 2016 Sep 1; 120:432-41.

15. Shir Mohammadi M, Nairn J. A. Balsa sandwich composite fracture study: Comparison of laminated to solid balsa core materials and debonding from thick balsa core materials. Journal of Composites Part B: Engineering. 2017 August 1; 122:165-172.

16. https://www.3accorematerials.com/uploads/documents/Flyer-Baltek-VBC-Prepress.pdf 17. Bailleres H, Denaud L, Butaud JC, McGavin RL. Experimental investigation on rotary peeling parameters of high density coconut wood. BioResources. 2015 Jun 25; 10(3):4978-96 18. ASTM D4442-07, Standard Test Methods for Direct Moisture Content Measurement of Wood and Wood-Base Materials, ASTM International, West Conshohocken, PA, 2007.

19. ASTM D3500-14, Standard Test Methods for Structural Panels in Tension, ASTM International, West Conshohocken, PA, 2014.

20. ASTM D3501-05a(2011), Standard Test Methods for Wood-Based Structural Panels in Compression, ASTM International, West Conshohocken, PA, 2011. 
21. ASTM D5379 / D5379M-12, Standard Test Method for Shear Properties of Composite Materials by the V-Notched Beam Method, ASTM International, West Conshohocken, PA, 2012.

22. ASTM D3039 / D3039M, Standard Test Method for Tensile Properties of Polymer Matrix Composite Materials, ASTM International, West Conshohocken, PA, 2008.

23. EN 1990 (2002) "Eurocode - Basis of structural design" The European Union Per Regulation 305/2011, Directive 98/34/EC, Directive 2004/18/EC

24. Wilk MB, Gnanadesikan R. Probability plotting methods for the analysis for the analysis of data. Biometrika. 1968 Mar 1; 55(1):1-7. 
Tables:

Table 1 Results of tensile experiments

\begin{tabular}{|c|c|c|}
\hline Specimens & Modulus (MPa) & Tensile strength $(\mathrm{MPa})$ \\
\hline T1-1 & 50 & 0.25 \\
\hline $\mathrm{T} 1-2$ & 82 & 0.51 \\
\hline $\mathrm{T} 1-3$ & 52 & 0.18 \\
\hline $\mathrm{T} 1-4$ & 88 & 0.32 \\
\hline $\mathrm{T} 1-5$ & 57 & 0.20 \\
\hline T1-6 & 57 & 0.27 \\
\hline $\mathrm{T} 1-7$ & 53 & 0.28 \\
\hline $\mathrm{T} 1-8$ & 98 & 0.47 \\
\hline T1-9 & 75 & 0.36 \\
\hline $\mathrm{T} 1-10$ & 41 & 0.30 \\
\hline Mean \pm standard dev. & $65 \pm 19$ & $0.31 \pm 0.12$ \\
\hline Coefficient of variation (\%) & 29 & 38 \\
\hline $\mathrm{T} 2-1$ & 1129 & 7.78 \\
\hline $\mathrm{T} 2-2$ & 1631 & 13.84 \\
\hline $\mathrm{T} 2-3$ & 896 & 7.72 \\
\hline $\mathrm{T} 2-4$ & 2650 & 16.72 \\
\hline $\mathrm{T} 2-5$ & 1359 & 11.28 \\
\hline $\mathrm{T} 2-6$ & 965 & 7.37 \\
\hline $\mathrm{T} 2-7$ & 1959 & 15.23 \\
\hline $\mathrm{T} 2-8$ & 2501 & 10.87 \\
\hline T2-9 & 1795 & 13.95 \\
\hline $\mathrm{T} 2-10$ & 1071 & 6.62 \\
\hline Mean \pm standard dev. & $1596 \pm 627$ & $11.14 \pm 3.66$ \\
\hline Coefficient of variation (\%) & 39 & 32 \\
\hline T3-1 & 1362 & 10.07 \\
\hline T3-2 & 1934 & 14.45 \\
\hline T3-3 & 1557 & 7.84 \\
\hline T3-4 & 1622 & 8.47 \\
\hline T3-5 & 2378 & 21.42 \\
\hline T3-6 & 3178 & 18.09 \\
\hline T3-7 & 2019 & 10.09 \\
\hline T3-8 & 2020 & 14.43 \\
\hline T3-9 & 1772 & 15.26 \\
\hline $\mathrm{T} 3-10$ & 2553 & 15.63 \\
\hline Mean \pm standard dev. & $2039 \pm 540$ & $13.58 \pm 4.40$ \\
\hline Coefficient of variation (\%) & 26 & 32 \\
\hline
\end{tabular}


Table 2. Results of compressive experiments

\begin{tabular}{ccccc}
\hline ID & Specimens & Modulus (MPa) & Strength (MPa) & Buckling stress (MPa) \\
\hline 1 & C1-1 & 81 & 0.69 & 0.38 \\
2 & C1-2 & 71 & 0.72 & 0.36 \\
3 & C1-3 & 86 & 0.71 & 0.39 \\
4 & C1-4 & 80 & 0.69 & 0.39 \\
5 & C1-5 & 63 & 0.54 & 0.37 \\
6 & C1-6 & 82 & 0.69 & 0.41 \\
\hline \multicolumn{2}{l}{ Mean \pm standard dev. } & $77 \pm 8$ & $0.67 \pm 0.07$ & $0.38 \pm 0.02$ \\
\hline Coefficient of variation (\%) & 10 & 10 & 0.05 \\
\hline 1 & C2-1 & 2229 & 7.61 & 7.16 \\
2 & C2-2 & 2794 & 8.71 & 8.40 \\
3 & C2-3 & 2894 & 6.28 & 5.93 \\
4 & C2-4 & 2311 & 8.26 & 7.83 \\
5 & C2-5 & 2240 & 7.61 & 7.36 \\
6 & C2-6 & 2038 & 6.81 & 6.57 \\
\hline \multicolumn{2}{l}{ Mean \pm standard dev. } & $2418 \pm 344$ & $7.55 \pm 344$ & $7.21 \pm 0.88$ \\
\hline Coefficient of variation (\%) & 14 & 12 & 12 \\
\hline 1 & C3-1 & 2592 & 9.42 & N/A \\
2 & C3-2 & 3064 & 10.62 & N/A \\
3 & C3-3 & 3648 & 13.62 & N/A \\
4 & C3-4 & 2176 & 8.21 & N/A \\
5 & C3-5 & 2905 & 12.34 & N/A \\
6 & C3-6 & 3711 & 13.08 & N/A \\
\hline \multicolumn{2}{l}{ Mean \pm standard dev. } & $3016 \pm 597$ & $11.22 \pm 2.15$ & N/A \\
\hline Coefficient of variation (\%) & 20 & 19 & \\
\hline
\end{tabular}


Table 3. Results of shear experiments

\begin{tabular}{|c|c|c|c|c|}
\hline ID & Specimens & Modulus (MPa) & Strength $(\mathrm{MPa})$ & Strength at 0.05 strain $(\mathrm{MPa})$ \\
\hline 1 & S1-1 & 53 & 1.37 & NA \\
\hline 2 & $\mathrm{~S} 1-2$ & 85 & 1.79 & NA \\
\hline 3 & $\mathrm{~S} 1-3$ & 69 & 1.16 & NA \\
\hline 4 & $\mathrm{~S} 1-4$ & 94 & 1.74 & NA \\
\hline 5 & S1-5 & 58 & 1.20 & NA \\
\hline \multicolumn{2}{|c|}{ Mean \pm standard dev. } & $72 \pm 17$ & $1.45 \pm 0.30$ & NA \\
\hline \multicolumn{2}{|c|}{ Coefficient of variation (\%) } & 24 & 21 & NA \\
\hline 1 & S2-1 & 43 & 1.88 & 0.88 \\
\hline 2 & S2-2 & 49 & 1.98 & 1.07 \\
\hline 3 & S2-3 & 59 & 2.44 & 1.31 \\
\hline 4 & S2-4 & 46 & 2.00 & 0.84 \\
\hline 5 & S2-5 & 40 & 1.77 & 1.07 \\
\hline \multicolumn{2}{|c|}{ Mean \pm standard dev. } & $48 \pm 7$ & $1.92 \pm 0.10$ & $1.03 \pm 0.19$ \\
\hline \multicolumn{2}{|c|}{ Coefficient of variation (\%) } & 14 & 5 & 18 \\
\hline 1 & S3-1 & 26 & 0.64 & NA \\
\hline 2 & S3-2 & 13 & 0.51 & NA \\
\hline 3 & S3-3 & 26 & 0.57 & NA \\
\hline 4 & S3-4 & 25 & 0.63 & NA \\
\hline 5 & S3-5 & 22 & 0.52 & NA \\
\hline \multicolumn{2}{|c|}{ Mean \pm standard dev. } & $23 \pm 5$ & $0.57 \pm 0.06$ & NA \\
\hline \multicolumn{2}{|c|}{ Coefficient of variation (\%) } & 22 & 10 & $\mathrm{NA}$ \\
\hline 1 & S4-1 & 10 & 0.31 & NA \\
\hline 2 & S4-2 & 20 & 0.36 & NA \\
\hline 3 & S4-3 & 12 & 0.25 & NA \\
\hline 4 & S4-4 & 17 & 0.37 & NA \\
\hline 5 & S4-5 & 21 & 0.36 & NA \\
\hline \multicolumn{2}{|c|}{ Mean \pm standard dev. } & $16 \pm 5$ & $0.33 \pm 0.05$ & NA \\
\hline \multicolumn{2}{|c|}{ Coefficient of variation (\%) } & 31 & 15 & NA \\
\hline
\end{tabular}


Table 4 . Values of $k_{n}$ for $5 \%$ characteristic value [23]

\begin{tabular}{cccccccccccc}
\hline$n$ & 1 & 2 & 3 & 4 & 5 & 6 & 8 & 10 & 20 & 30 & $\infty$ \\
\hline$k_{(\mathrm{n})}$ & 2.31 & 2.01 & 1.89 & 1.83 & 1.80 & 1.77 & 1.74 & 1.72 & 1.68 & 1.67 & 1.64 \\
\hline
\end{tabular}

Table $5.5 \%$ characteristic values

\begin{tabular}{ccccccc}
\hline \multirow{2}{*}{ Configuration } & \multicolumn{2}{c}{ Eurocode } & \multicolumn{2}{c}{ Normal } & \multicolumn{2}{c}{ Weibull } \\
\cline { 2 - 7 } & Modulus & Strength & Modulus & Strength & Modulus & Strength \\
\hline T1 & 33 & 0.13 & 34 & 0.14 & 34 & 0.14 \\
T2 & 517 & 4.84 & 564 & 5.11 & 648 & 5.45 \\
T3 & 1110 & 6.02 & 1151 & 6.35 & 1083 & 6.61 \\
C1 $^{*}$ & 62 & 0.35 & 63 & 0.35 & 65 & 0.35 \\
C2 $^{*}$ & 1808 & 5.65 & 1851 & 5.76 & 1779 & 5.68 \\
C3 & 1959 & 7.41 & 2034 & 7.68 & 2046 & 7.84 \\
S1 & 40 & 0.92 & 43 & 0.97 & 44 & 0.97 \\
S2 & 34 & 0.69 & 35 & 0.73 & 33 & 0.70 \\
S3 & 13 & 0.47 & 14 & 0.47 & 16 & 0.47 \\
S4 & 7 & 0.24 & 8 & 0.25 & 9 & 0.26 \\
\hline
\end{tabular}

* strength calculated based on buckling stress.

+ strength calculated based on strength at 0.05 strain. 
Figures:

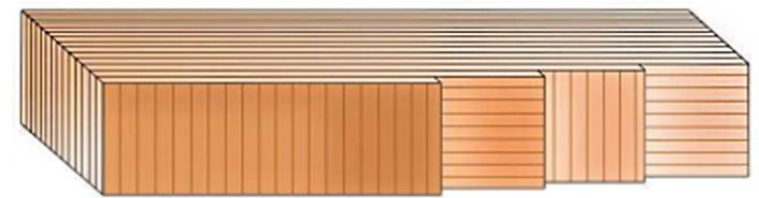

Fig. 1. Balsa wood product BALTEK ${ }^{\circledR}$ VBC with veneer layers alternatingly oriented in $0^{\circ} / 90^{\circ}$ grain directions

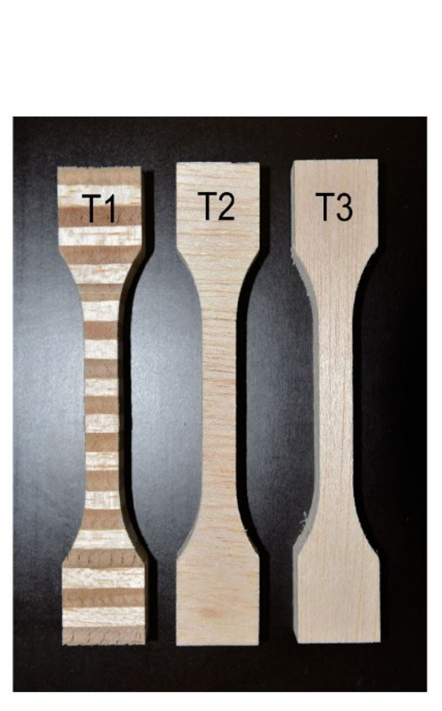

(a)

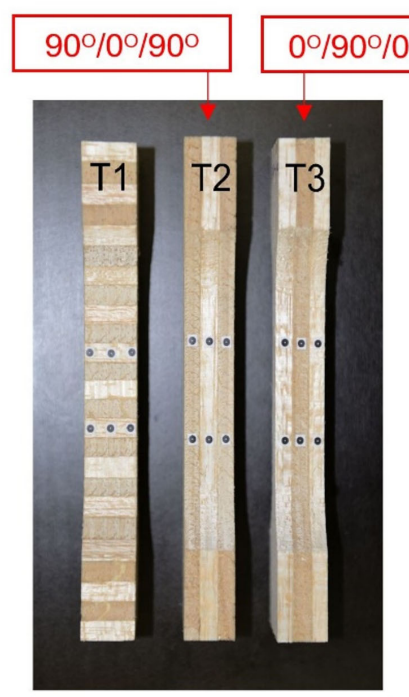

(b)

Fig. 2. (a) Front view and (b) side view of tensile specimens T1, T2, T3 


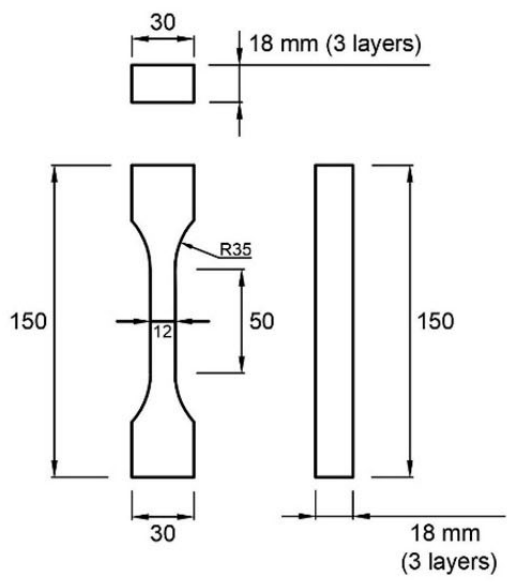

(a)

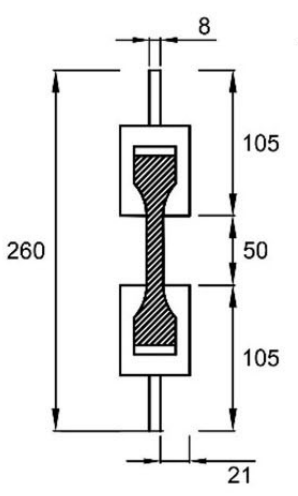

(b)

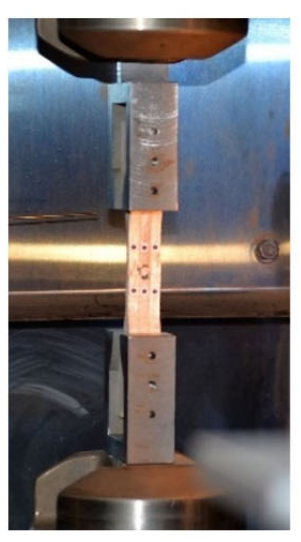

(c)

Fig. 3. (a) Dimensions of tensile specimens, and (b) fixture for applying tensile load (in mm), (c) experimental set-up of tensile experiments

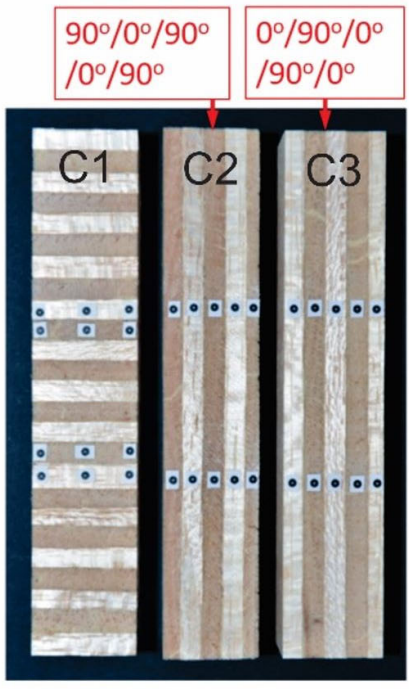

(a)
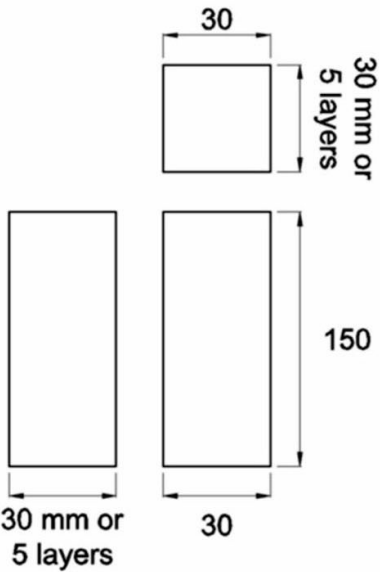

(b)

Fig. 4. (a) Configurations of compressive specimens $\mathrm{C} 1, \mathrm{C} 2$ and $\mathrm{C} 3$, (b) dimensions 


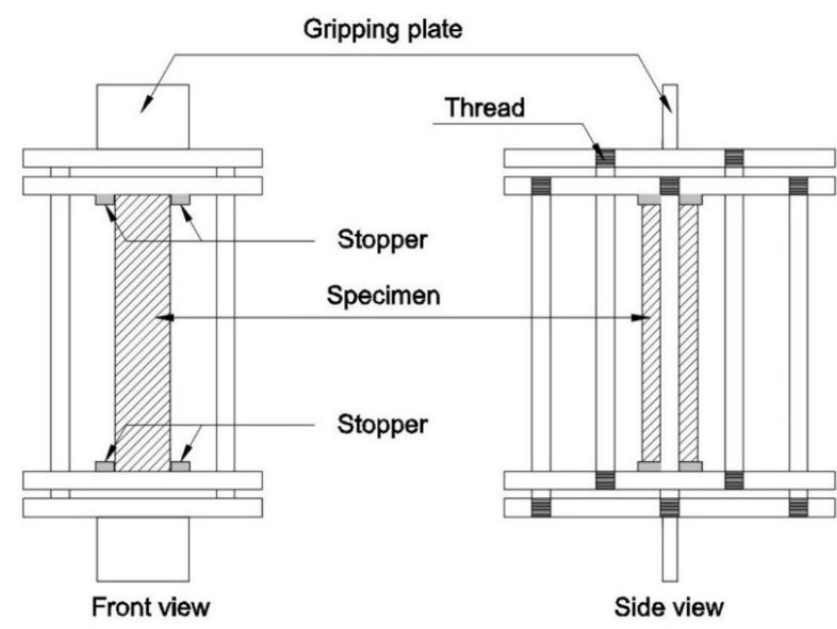

(a)

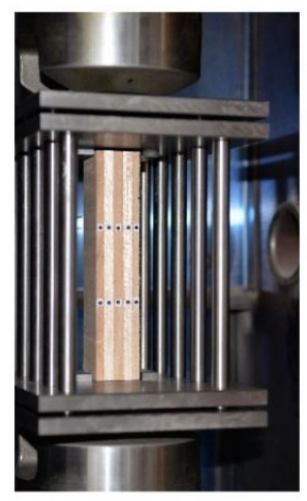

(b)

Fig. 5. (a) Fixture for applying compressive load, (b) experimental set-up of compressive experiments

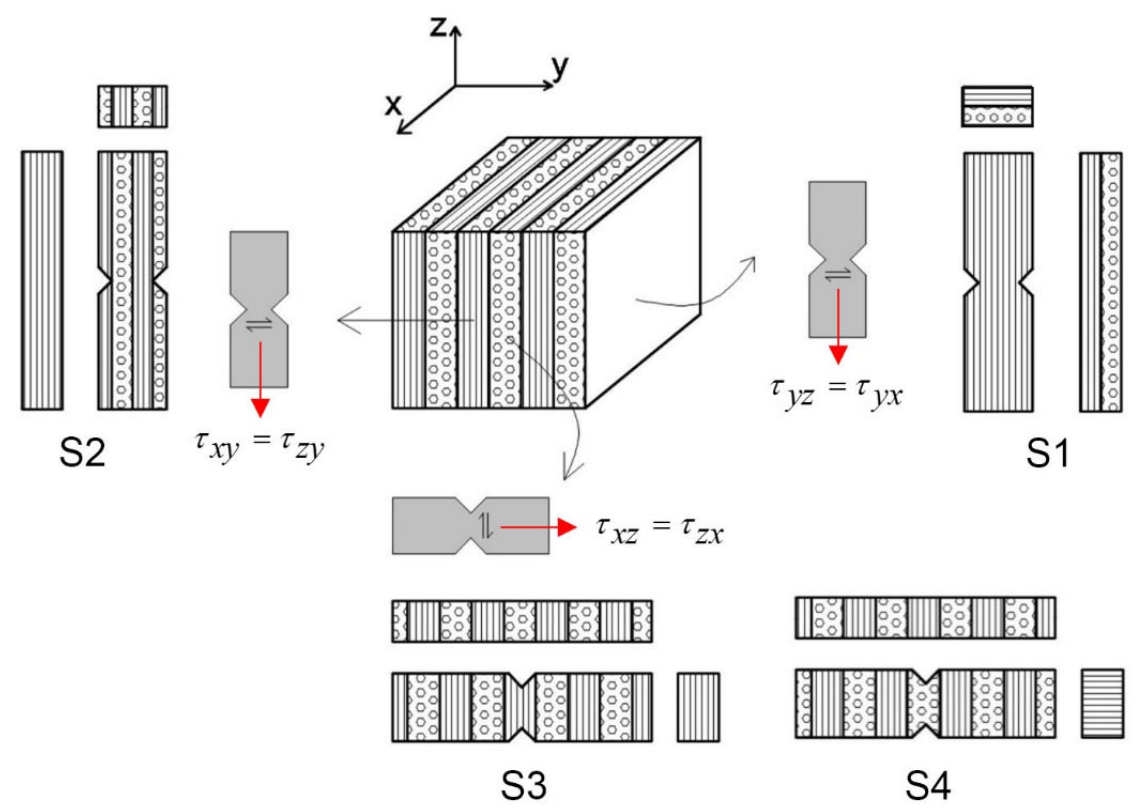

Fig. 6. Schematic of potential shear specimen configurations and shear stress directions 

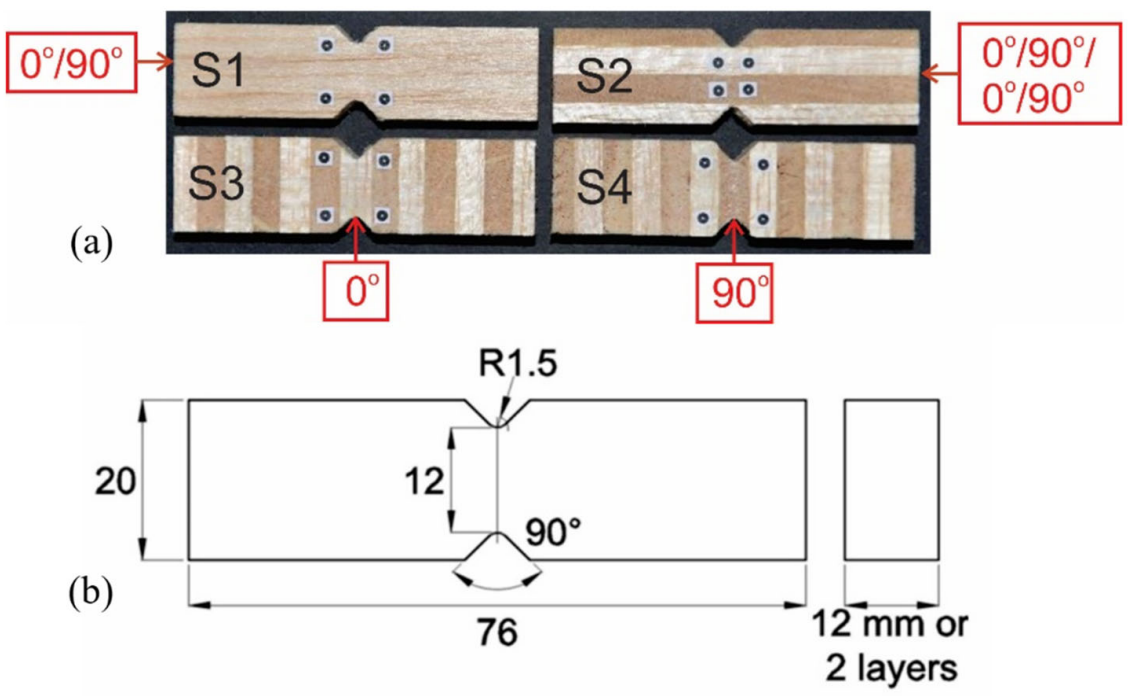

Fig. 7. (a) Configurations of shear specimens $\mathrm{S} 1, \mathrm{~S} 2, \mathrm{~S} 3$ and $\mathrm{S} 4$, (b) dimensions

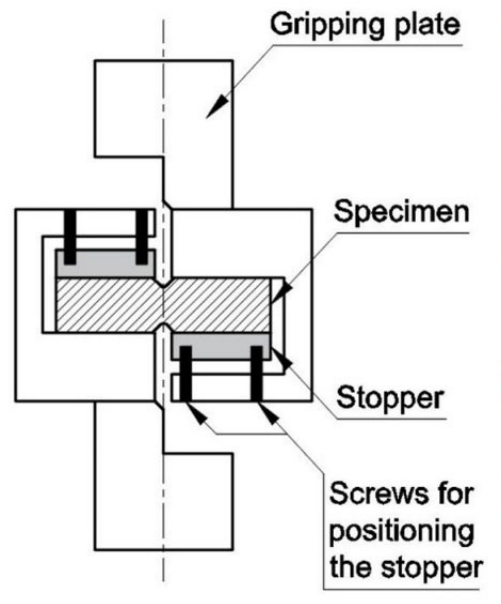

(a)

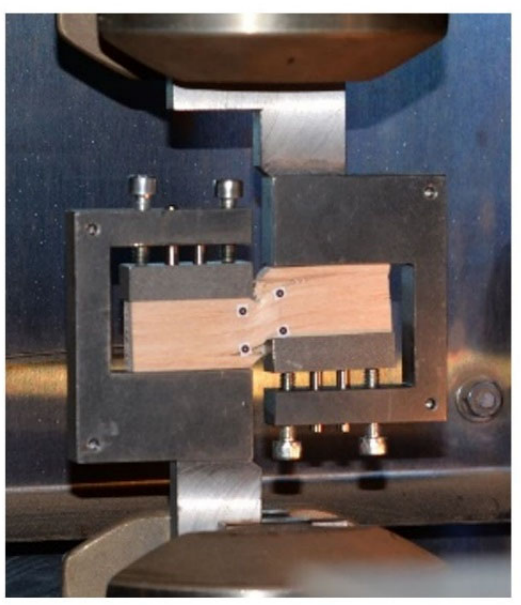

(b)

Fig. 8. Fixture and experimental set-up for shear loading 


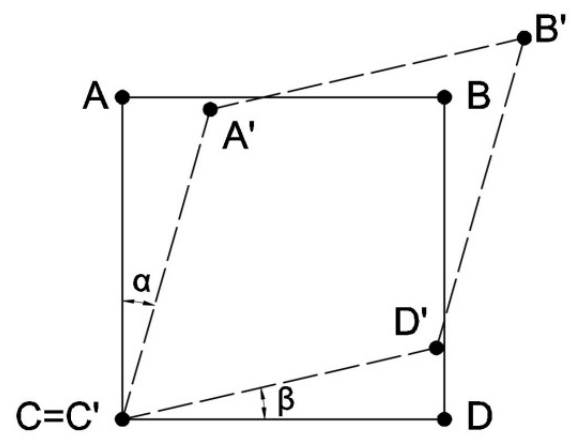

Fig. 9. Determination of shear strain using video extensometer [2]
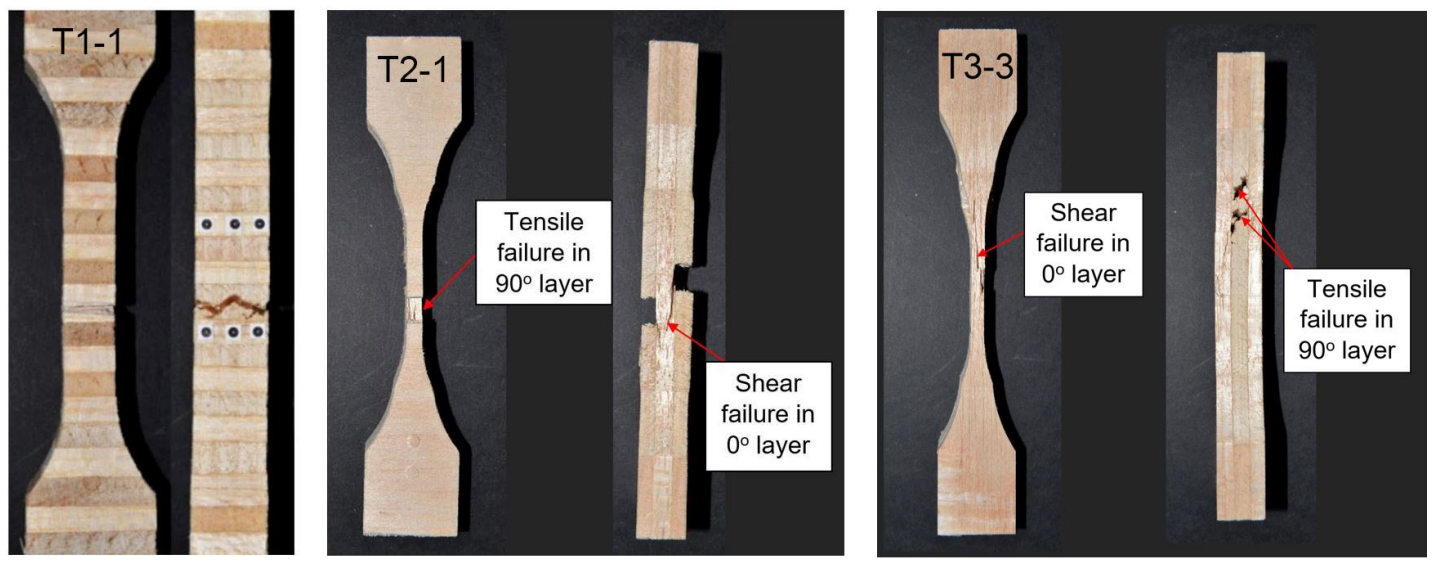

Fig. 10. Typical failure modes of $\mathrm{T} 1, \mathrm{~T} 2$ and $\mathrm{T} 3$ specimens 


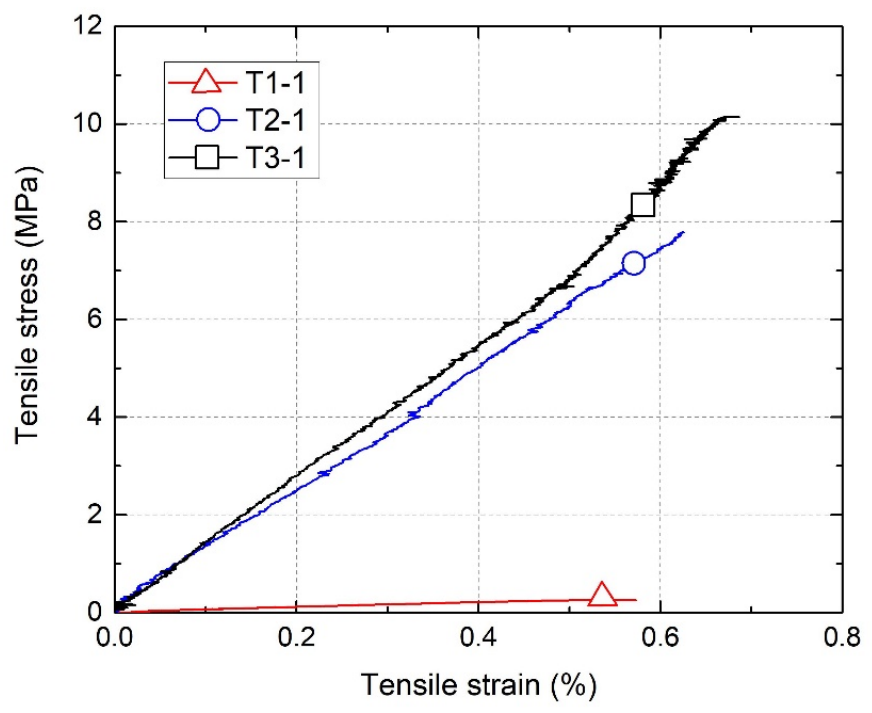

Fig. 11. Tensile stress-strain responses of selected T1, T2 and T3 specimens

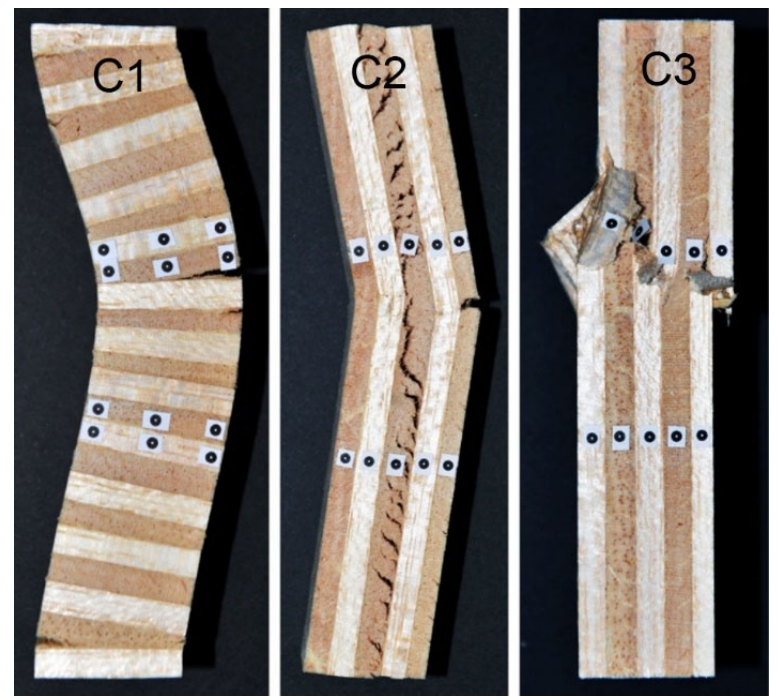

Fig. 12. Typical failure modes of $\mathrm{C} 1, \mathrm{C} 2$ and $\mathrm{C} 3$ specimens 


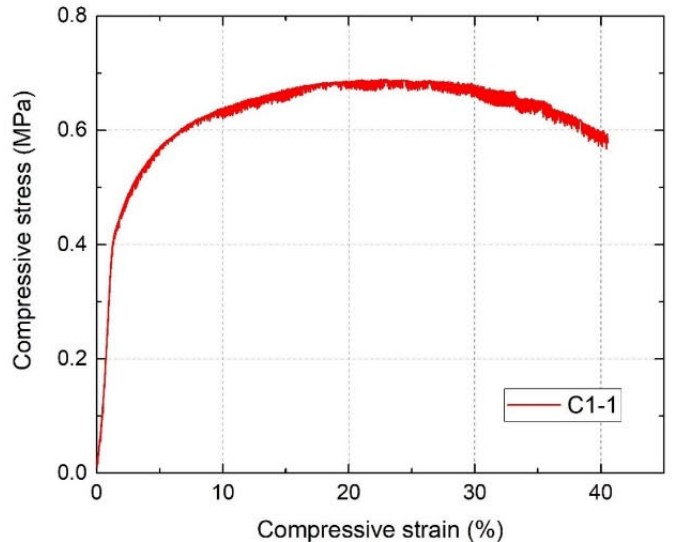

(a)

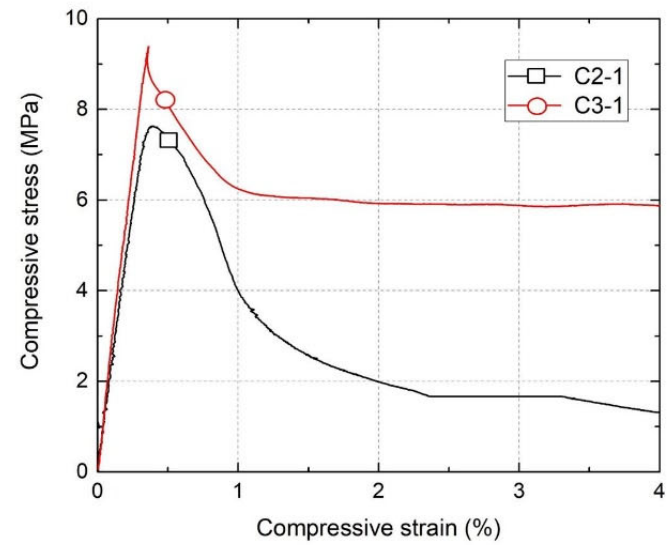

(b)

Fig. 13. Compressive stress-strain curves of (a) $\mathrm{C} 1$ and (b) $\mathrm{C} 2$ and $\mathrm{C} 3$

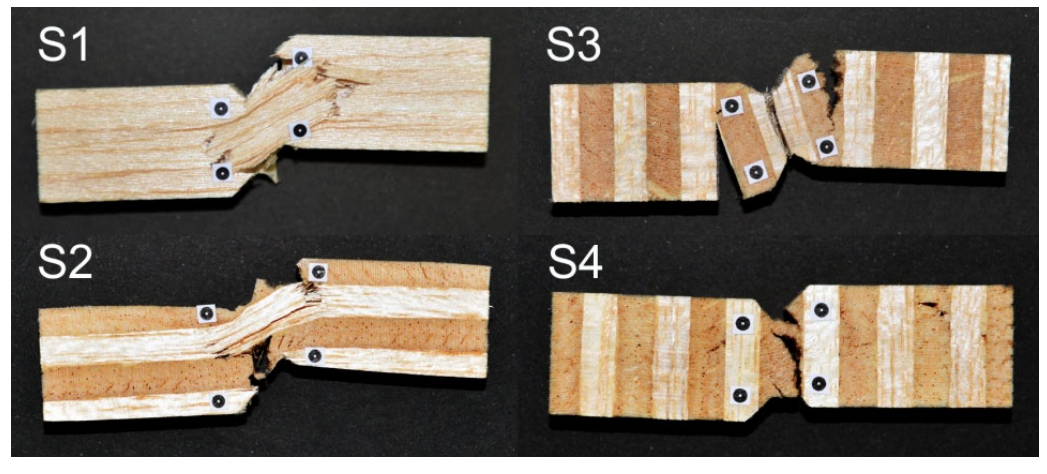

Fig. 14. Failure modes of S1, S2, S3 and S4 specimens 


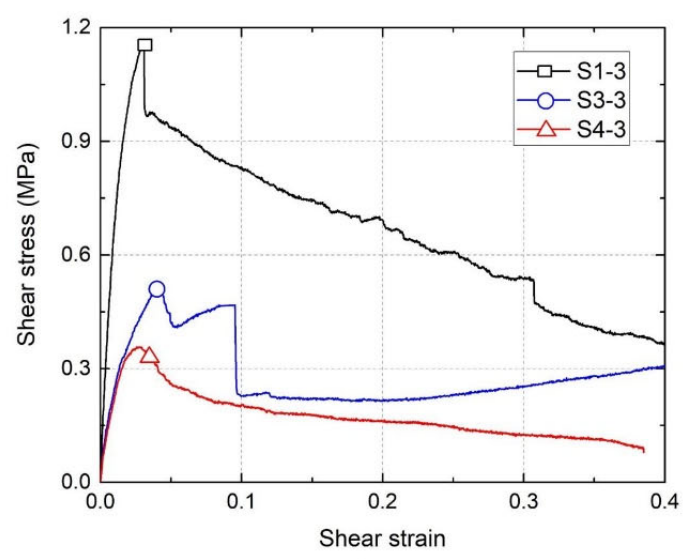

(a)

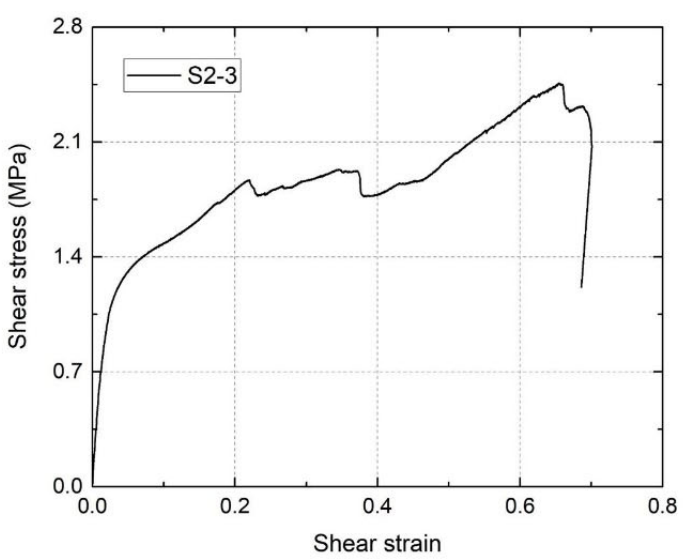

(b)

Fig. 15. Shear stress-strain curves of (a) S1, S3 and S4 and (b) S2 specimens

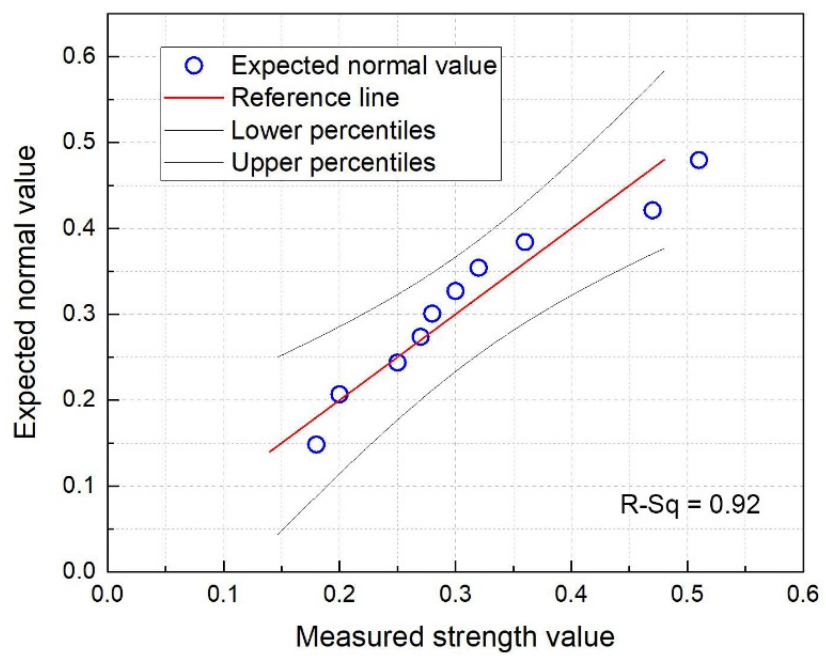

Fig. 16. Q-Q plot of strength data of T1 specimens vs normal distribution 


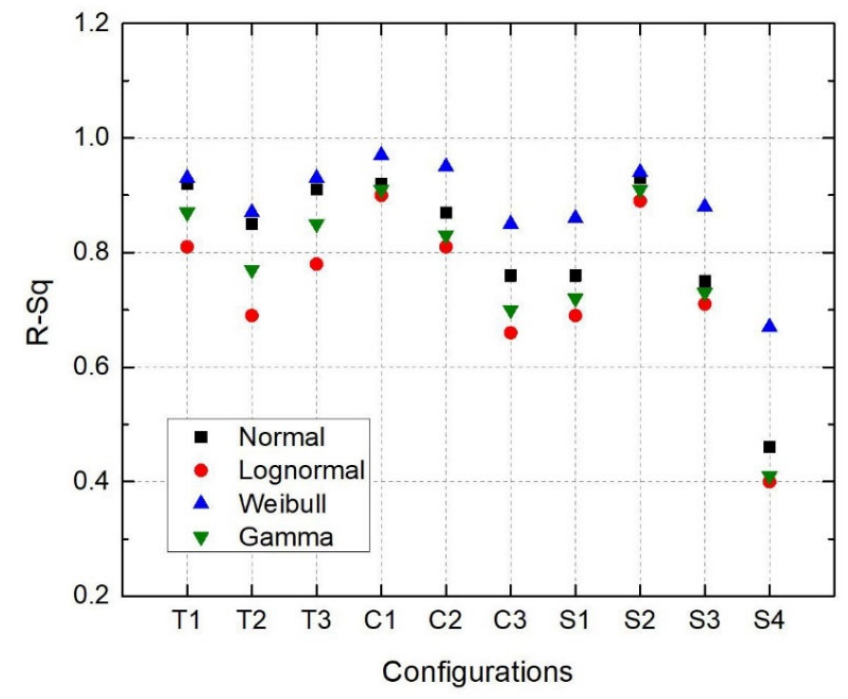

Fig. 17. R-squared values derived from Q-Q plots of all strength data

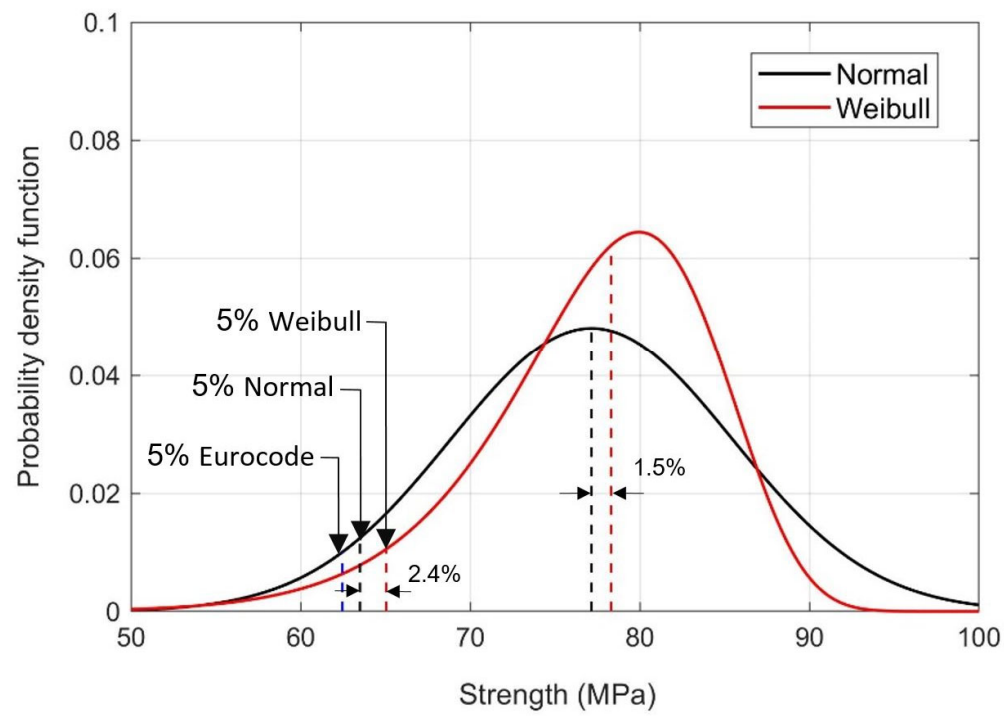

Fig. 18. Comparison between 5\% characteristic modulus of $\mathrm{C} 1$ corresponding to Weibull, normal and Euorocode EN1990 [23]. 